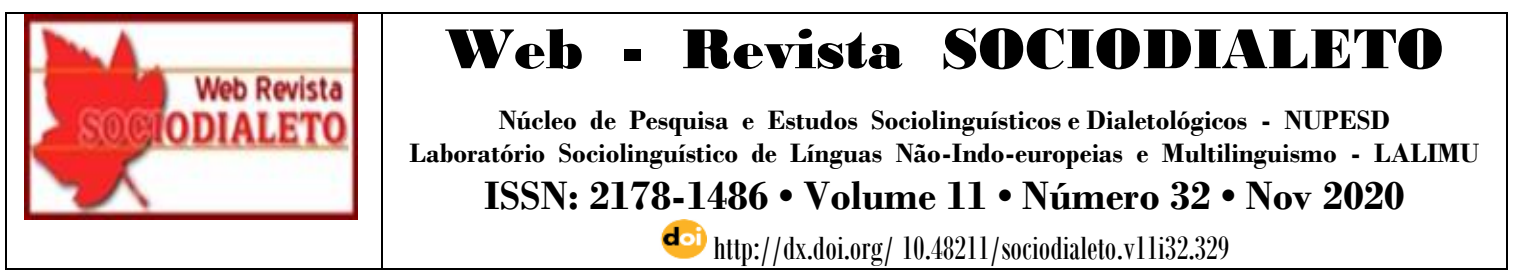

\title{
A TOPONÍMIA INDÍGENA DOS ACIDENTES RURAIS HUMANOS DO MUNICÍPIO DE CORONEL SAPUCAIA - MS: UM ESTUDO ETNOLINGUÍSTICO
}

\author{
Aline dos Santos Almeida (UFGD) ${ }^{1}$ \\ aline.almeida210@gmail.com \\ Marilze Tavares (UFGD) ${ }^{2}$ \\ marilzetavares@ufgd.edu.br
}

\begin{abstract}
RESUMO: Este trabalho se insere na área dos estudos do léxico, mais especificamente na área da Toponímia, que tem como objetivo realizar investigações sobre a nomeação do espaço e dos acidentes geográficos físicos ou humanos de áreas rurais e urbanas. No recorte tomado para esta pesquisa, o objetivo foi investigar a nomeação de acidentes humanos da área rural do município de Coronel Sapucaia - MS. Estando o município em uma região complexa linguisticamente em razão de localizar-se na fronteira com o Paraguai e contar com a presença de comunidade indígena, a hipótese é que a realidade linguística estaria refletida na nomeação de espaços. Para a constituição do corpus, foram coletados 86 nomes de fazendas, sítios e colônia do mapa do IBGE (2010), escala 1:100.000. A análise demonstrou a ocorrência significativa de topônimos indígena (sobretudo, guarani) e híbridos com elementos de procedência da língua portuguesa e de línguas indígenas, o que foi, em certa medida, associado à presença indígena na região e à fronteira com o Paraguai, país cujas línguas oficiais são o guarani e o espanhol.
\end{abstract}

PALAVRAS-CHAVE: Léxico; Cultura; Toponímia Indígena; Coronel Sapucaia - MS

\begin{abstract}
This work includes the lexicon studies area, more specific to the area of Toponymy, which aims to carry out investigations on space naming and physical or human geographical accidents in rural and urban areas. It was not necessary to resort to this research, the objective was to investigate the appointment of human accidents in the rural area of the municipality of Coronel Sapucaia - MS. Since the municipality is in a linguistically complex region due to its location on the border with Paraguay and the presence of an indigenous community, the hypothesis is that the linguistic reality would be reflected in the naming of spaces. For the constitution of the corpus, 86 farm, site, and colony names from the IBGE map (2010), scale 1: 100,000, were collected. The analysis demonstrated the significant occurrence of indigenous toponyms (mainly, Guarani) and hybrids with elements from the Portuguese language and indigenous languages, which was, to some extent, associated with the indigenous presence in the region and the border with Paraguay, the country whose official languages are Guarani and Spanish.
\end{abstract}

KEYWORDS: Lexicon; Culture; Indigenous Toponymy; Coronel Sapucaia - MS.

\section{Introdução}

\footnotetext{
${ }^{1}$ Graduanda em Letras pela Universidade Federal da Grande Dourados (UFGD).

${ }^{2}$ Doutora em Estudos da Linguagem. Docente da Universidade Federal da Grande Dourados (UFGD).
} 
A Toponímia se constitui como uma área de conhecimento que tem desenvolvido muitas pesquisas sob diversas perspectivas. Isso ocorre, sobretudo, pelo seu caráter interdisciplinar, ou seja, nos estudos toponímicos, ainda que o enfoque maior seja o linguístico - se a investigação for desenvolvida por pesquisadores da área de Letras, por exemplo -, outras questões como aspectos geográficos, sociais, históricos, psicológicos, culturais de modo geral poderão estar envolvidas na pesquisa.

No caso deste estudo, foi necessário ter em vista, principalmente, aspectos geográficos e culturais, uma vez que o local de onde foram coletados os dados está na fronteira com o Paraguai, país que tem como línguas oficiais o guarani e o espanhola. Além disso, foi preciso considerar também a presença da comunidade indígena Taquaperi, da etnia Guarani (falante de língua guarani e de língua portuguesa). Assim, na região da pesquisa se observa uma realidade linguístico-cultural resultada do contato de línguas que, por sua vez, resulta em situações de bilinguismo e de multilinguismo português/guarani, português/espanhol, guarani/espanhol.

Entende-se que o resultado do contato existente pode ser notado em muitas situações de interação linguística dos falantes, inclusive no processo de nomeação dos espaços geográficos - que também é uma importante operação linguística dos falantes. Assim, considerando esse contexto, o objetivo do trabalho foi realizar um estudo dos topônimos de acidentes humanos da área rural nos quais poderiam estar refletidos os aspectos linguístico-culturais mencionados.

Como a pesquisa está vinculada ao projeto ATEMS - Atlas Toponímico do Estado de Mato Grosso do Sul e ao projeto DTMS - Dicionário de Topônimos de Mato Grosso do Sul, a metodologia e o embasamento teórico são os mesmos utilizados nas investigações ligadas a esses projetos. Desse modo, os topônimos foram coletados de cartas do IBGE (2010), escala 1:100.000 e analisados, inicialmente, seguindo-se os pressupostos de Dick (1990) especialmente quanto à motivação semântica. Para outras reflexões, recorreu-se, especialmente, a Sapir (1961), linguista que aprofunda questões concernentes à relação entre língua e cultura. 
Convém registrar que, durante o desenvolvimento desta pesquisa, tomou-se conhecimento, por meio de um resumo publicado $^{3}$, do trabalho intitulado Análise toponímica dos municípios sul-mato-grossenses: Coronel Sapucaia, Paranhos, Sete Quedas, Japorã, Mundo Novo e Eldorado (MARCHETTO; FIGUEIREDO, 2016). O resume se refere a um trabalho de Iniciação Científica que tomou para estudo a toponímia de seis município.

Neste artigo, foram tomados apenas os nomes indígenas ou híbridos com elementos indígenas de um desses municípios que também aparece na pesquisados autores citados. Trata-se, portanto, de um recorte distinto e bem específico.

Na sequência, estão informações sobre o local da pesquisa, alguns pressupostos teóricos, a análise dos nomes e as considerações finais.

\section{Sobre o local da pesquisa: Coronel Sapucaia - MS}

Coronel Sapucaia é uma cidade brasileira da Região Centro-Oeste, que pertence ao sul do estado de Mato Grosso do Sul - MS e situa-se a cerca de $420 \mathrm{~km}$ da capital sul-mato-grossense, Campo Grande. Está na linha de fronteira seca com a cidade paraguaia de Capitán Bado, pertencente ao departamento de Amambay. Conforme o censo demográfico realizado pelo Instituto Brasileiro de Geografia e Estatística (IBGE), em 2010, Coronel Sapucaia contava com cerca de 14.064 habitantes; atualmente (dados de 2019), estima-se que a população esteja em torno de 15.253 habitantes. A figura a seguir mostra a localização da cidade no MS.

Figura 01 - Localização de Coronel Sapucaia no estado de Mato Grosso do Sul.

\footnotetext{
${ }^{3}$ Resumo disponível em https://anaisonline.uems.br/index.php/enic/article/view/3768. Acesso em 21 de setembro de 2020.
} 


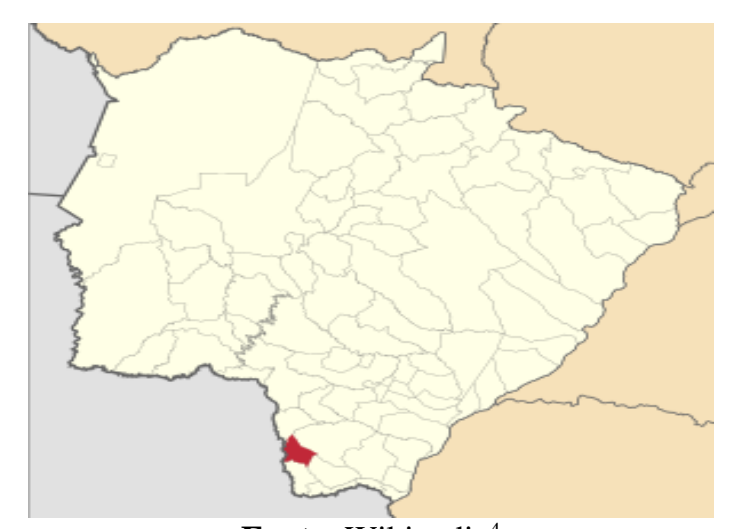

Fonte: Wikipedia ${ }^{4}$

Conforme dados históricos registrados no site do IBGE, Coronel Sapucaia, antes de ser conhecida por esse nome, já fez parte dos distritos considerados como "Patrimônio da União" do município de Ponta Porã, sob o nome de Nhu-Verá (nome de origem guarani, que significa "campo que brilha"); seu território servia de base à Companhia Mate Laranjeira, que a utilizava para fins de exploração de erva-mate sob a autorização do Império, em 1889. Em 02 de dezembro de 1938, foi expedida uma certidão para a criação do Distrito de Paz de Antônio João que, em 6 de dezembro de 1948, passou a pertencer à comarca de Amambai. Após vários anos de exploração da erva-mate por terras sul-mato-grossense, em 1947 a empresa Mate Laranjeira deixou a região de Antônio João, possibilitando a instalação de imigrantes e de trabalhadores que já se encontravam no território. No dia 31 de dezembro de 1968, com a nova fixação da Divisão Administrativa Judiciária Territorial, o Distrito de Antônio João passou a pertencer à comarca de Amambai, já sob a denominação de Coronel Sapucaia, sendo elevado à categoria de município pela Lei Estadual n. 623, de 30 de dezembro de 1985, desmembrado do município de Amambaí

A influência fronteiriça é notada e refletida na cultura da população sapucaiense e badeña (designações para os habitantes de Coronel Sapucaia e Capitán Bado, respectivamente) principalmente na variedade linguística local, pois a mescla das línguas faladas nesse território resulta em um hibridismo linguístico entre português, guarani e espanhol que pode ser notado nas diversas situações de interação dos

\begin{tabular}{l}
\hline $\begin{array}{l}\text { WIKIPÉDIA. } \\
4\end{array}$ Coronel \\
<https://pt.wikipedia.org/wiki/Ficheiro:Brazil_Mato_Grosso_do_Sul_Coronel_Sapucaia_location_map.sv \\
g>. Acesso em: 05 mai. 2020.
\end{tabular}


indivíduos da região. Nesse sentido, a fronteira passa a ser apenas uma designação política e econômica: na prática, essa fronteira é rompida pela confluência populacional de brasileiros, paraguaios e indígenas (haja vista que a Aldeia Taquaperi se encontra próxima às cidades).

\section{A relação entre língua e aspectos externos}

Muitos linguistas, durante muitos anos, consideravam que a língua era dotada de um caráter homogêneo, ou seja, a língua era independente de fatores externos, podendo ser explicada apenas por ela mesma; o próprio Saussure ${ }^{5}$, ao apresentar sua dicotomia língua e discurso (langue e parole), no início do século $\mathrm{XX}$, pautou seus estudos na língua, pois entendia que o discurso era complexo demais para um estudo descritivo. A partir dessa opção metodológica, muitas questões ficaram de fora dos principais estudos linguísticos por um longo tempo.

Nesse sentido, a exclusão do estudo acerca da influência social e cultural sobre a língua e a crença no seu caráter homogêneo seguiram-se nos anos subsequentes, ganhando notabilidade nos estudos de outros linguistas como Bloomfield (que adotou um enfoque estruturalista, utilizando como base a teoria behaviorista de Skinner ${ }^{6}$ ) e de Noam Chomsky (criador do modelo gerativista, que pressupunha a existência de um falante-ouvinte-ideal e de uma comunidade linguística homogênea).

Assim, após uma série de pesquisas linguísticas nas quais os fatores social e cultural eram praticamente excluídos, começam a se destacarem estudiosos que se preocuparam em demonstrar a relação entre língua, cultura e ambiente. Entres os linguistas adeptos dessa perspectiva, um dos mais célebres é Edward Sapir, que defende a ideia de que "há uma forte tendência a atribuir muitos elementos da cultura humana à influência do ambiente em que se acham situados os participantes dessa cultura"

\footnotetext{
${ }^{5}$ Para esta afirmação, leva-se em conta a publicação de seu livro póstumo Curso de Linguística Geral (1917).

${ }^{6}$ Para Skinner, as ações humanas seriam motivadas por uma espécie de "condicionamento operante", ou seja, a ideia de recompensa ou punição é o que molda o comportamento e estimula a necessidade de realizar tal ação.
} 
(SAPIR, 1961, p.43). Sendo a língua um elemento de destaque na cultura de qualquer povo, já é possível compreender que aspectos do ambiente estariam refletidos na língua.

Não obstante, para que o ambiente exerça influência na cultura de um povo, é necessário que essa influência seja completa, ou seja, que ela abarque o todo de uma determinada comunidade, como uma espécie de acordo social:

É duvidoso que mesmo um único indivíduo seja suscetível a uma influência ambiental inteiramente desacompanhada de influências de outra espécie [...]. Continua de pé, entretanto, o ponto crucial de que, nas sociedades de fato existentes, uma influência ambiental, mesmo do caráter mais simples, é sempre consolidada ou mudada pelas fôrças sociais (SAPIR, 1961, p. 44).

No que diz respeito mais especificamente à língua, o autor esclarece que o termo "ambiente" deve ser utilizado para especificar tanto os fatores físicos quanto os sociais que a influenciam. E essa influência pode ser notada mais intensamente no léxico, uma vez que, conforme o autor, “[...] o léxico completo de uma língua pode se considerar, na verdade, como o complexo inventário de tôdas as idéias, interêsses e preocupações que açambarcam a atenção da comunidade" (SAPIR, 1961, p. 44-45).

Assim, entende-se que no léxico estão refletidos, de forma mais evidente, os fatores ambientais, pois cada língua reflete o recorte de um ambiente visando atender aos interesses dos seus falantes, suas necessidades de interação social e referências ao ambiente físico e social onde habitam. Os nomes próprios de lugar, ou seja, os topônimos, fazem parte do léxico de uma língua e, nesse sentido, será possível visualizar, em um conjunto de designativos geográficos, essa influência do ambiente (seja físico seja social).

\section{A nomeação dos lugares e a Toponímia como área de investigação}

Desde o momento em que o homem desenvolveu a capacidade de fala e de comunicação, ele atribui nomes a coisas, lugares e pessoas. É algo inerente ao desenvolvimento social das comunidades ao longo da história. 
A nomeação dos lugares sempre foi atividade exercida pelo homem, desde os primeiros tempos alcançados pela memória humana. Obras antigas da História e da civilização mundiais colocam essa prática como costumeira, ainda que distinta, em certos pontos do processo denominativo vivido modernamente (DICK, 1987, p. 96).

Os critérios que cada sociedade adota ao nomear tudo o que lhe cerca são relativos, pois cada uma delas possui suas próprias características, suas próprias organizações e são influenciadas por fatores sociais diferentes. $\mathrm{O}$ fato é que, por serem os designativos geográficos tão importantes para o homem, tornou-se objeto de estudo de uma área específica da Linguística, a Toponímia. Isso não significa, entretanto, que apenas a Linguística será capaz de tratar um topônimo em toda a sua amplitude. Nesse sentido, alerta Dick:

Observando os diferentes sistemas culturais, em que topônimos, ou nomes próprios de lugares, se inscrevem como instrumentos hábeis de pesquisa, verifica-se que o sentido desses denominativos é o ponto de partida para investigações que, se, antes, se definiam apenas como linguísticas, hoje se inscrevem, também, nos campos da geografia, da antropologia, da psicossociologia, enfim, da cultura em geral para, num aprofundamento, procurar compreender a própria mentalidade do denominador, não só como elemento isolado, mas como projeção de seu grupo social (DICK, 1987, p. 97).

Sendo assim, para se compreender com maior precisão a motivação por trás das denominações e para se compreender a mentalidade do denominador ou da sociedade na qual está inserido, os pesquisadores do ramo da Toponímia necessitam não só de conhecimentos linguísticos, mas também, em muitas ocasiões, de conhecimentos interdisciplinares (da história, da Geografia, da Antropologia etc.) para explicar com maior eficácia um topônimo ou um conjunto de topônimos. Também sobre o nome próprio, o semanticista Ullmann registra:

O estudo dos nomes próprios que pode esclarecer muitos aspectos da história política, econômica e social, afirmou-se recentemente como um ramo da linguística quase independente, e tem seus congressos próprios e revistas especializadas. Esta ciência, conhecida como onomástica, tem duas divisões principais: a toponímia, estudo dos 


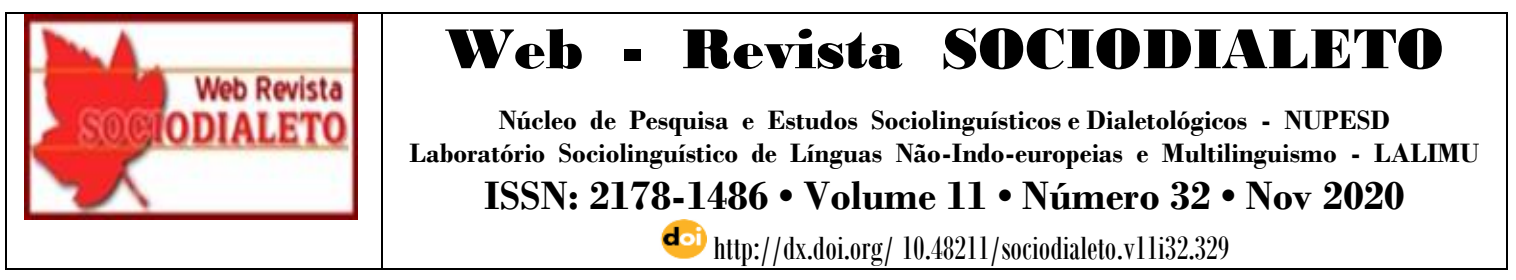

nomes de lugar, e a antroponímia, estudo dos nomes de pessoas (ULLMANN, 1961, p. 161).

Portanto, ao se desenvolverem pesquisas pelas quais se resgatem o valor original de um nome próprio, resgatam-se junto a ele uma série de fatores sociais que serão úteis a outras áreas de conhecimento científico com a finalidade de explicar ou complementar alguma informação já existente. Em outras palavras, ao se estudar antroponímia e toponímia, resgatam-se também aspectos da cultura de um povo.

Conforme Dubois (1973, p.90), a “Toponímia é a parte da linguística que se ocupa da origem dos nomes de lugares, de suas relações com a língua do país, com as línguas de outros países e com as línguas desaparecidas”. Sendo assim, a Toponímia é o ramo que se dedica a descobrir a origem dos nomes dos lugares, explicar a sua etimologia e esclarecer as motivações existentes, além de investigar possíveis influências linguísticas existentes na composição de um nome.

A Toponímia, portanto, atualmente, com orientações e perspectivas novas, é uma disciplina que se volta para a História, a Geografia, a Linguística, a Antropologia, a Psicologia Social e, até mesmo, à Zoologia, à Botânica, à Arqueologia, de acordo com a formação intelectual do pesquisador. Numa interpenetração de campos fenomenológicos específicos, ressalte, porém, o papel universalístico da disciplina (...) mas, no seu caso, torna-se muito particular a um determinado espaço, desde que envolve o homem que manipula a cultura desse meio, como produto, que dele é (DICK, 1990, p. II).

Dick (1990) disserta sobre a interdisciplinaridade do ramo, que une diversas áreas de conhecimento; o que definirá seus objetivos será a área da qual o pesquisador se origina. Essa universalidade científica trabalha com particularidades, já que, quando se opta por estudar o topônimo, opta-se por fazer um recorte no ambiente e das possibilidades de tratamento dos nomes geográficos.

Em geral, os topônimos são estudados, principalmente, quanto à sua motivação semântica, quanto à sua língua de origem, com destaque para a influência de línguas 
indígenas e quanto a sua estrutura formal. No que diz respeito à motivação, Dick propõe a seguinte forma de classificação:

Aceitando-se a repartição genérica dos fatos cósmicos em duas ordens de consequência - a física e a antropo-cultural - pode-se acatar a mesma duplicidade de visão para o enquadramento dos topônimos e, dentro dessa bi-compartimentação, situar as modalidades particularizantes, através de da formulação de uma terminologia técnica, composta do elemento "topônimo", antecedido de um outro elemento genérico, definidor da respectiva classe onomástica. Este elemento deverá conter a suficiente explicitação de sua substância ou a clareza lógica para justificar a escolha, em uma linha de comando virtual (DICK, 1990, p. 26).

Em termos mais compreensíveis, a autora discorre que os topônimos são divididos, inicialmente, em duas ordens: uma de natureza física (ligada ao ambiente) e outra de natureza antropo-cultural (ligada à cultura ou à representações humanas); sendo esses topônimos compostos por um termo genérico e por outro termo específico (o nome propriamente dito), ele deve ser classificado por outro elemento (uma subcategoria dentro das duas ordens citadas anteriormente) que deve esclarecer e justificar a motivação por trás da escolha de tal nome. Por exemplo, em Fazenda Guapeí o termo Fazenda é o elemento genérico (tipo de acidente) e Guapeí é o elemento específico (nome próprio); dentro da ordem física, ele é classificado como fitotopônimo (topônimo de índole vegetal) pelo fato do termo Guapeí significar "vitória-régia, planta ninfácea do Amazonas” (TIBIRIÇÁ, 1989, p. 103).

$\mathrm{Na}$ formação estrutural de alguns topônimos brasileiros percebem-se influências linguísticas advindas de outras línguas, principalmente do guarani e do tupi, línguas de origem indígena. Explica-se essa influência pelo fato de que a sociedade brasileira se desenvolveu em um território inicialmente pertencentes aos indígenas. Um embate cultural e territorial entre portugueses e indígenas deixou marcas permanentes na história e na cultura brasileira, refletindo-se também no léxico e, claro, na toponímia do país: 


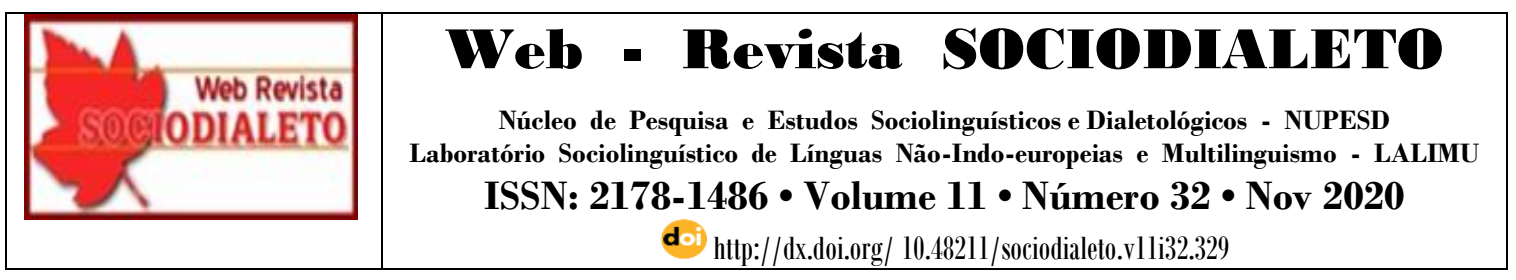

Não há quem desconheça a predominância do tupi em nossas denominações geográficas. As nossas montanhas, os nossos rios, as cidades, como os simples povoados, trazem geralmente nomes bárbaros que o gentio, dominador outrora, lhes aplicou, que os conquistadores respeitaram e que hoje são de todos preferidos, pois, não raro, trocam-se, substituem-se nomes portugueses de antigas localidades por outros de procedência indígena, às vezes lembrados ou compostos na ocasião, às vezes restaurados pelos amadores de coisas velhas e tradicionais (SAMPAIO, 1987, p. 63).

O estudo da Toponímia destaca-se, nesse quesito, como um ramo responsável por resgatar, através dos topônimos, a influência cultural indígena no léxico que, muitas vezes, acaba por se perder em meio à língua portuguesa, seja na forma de hibridismos, seja na forma de naturalização dos termos indígenas, que passam a ser utilizados rotineiramente. Sendo assim:

\begin{abstract}
Por sua vez, a Toponímia também prossegue na tarefa de preservação de tais onomásticos que, de modo autêntico e espontâneo, individualizaram os acidentes da terra, numa frequência que atinge a milhares de nomes. Se as denominações tópicas, mesmo quando relativas à realidade circundante atual, se revestem de uma significação histórico-cultural, muito maior, sem dúvida, será o seu papel, quando a análise efetuada possibilitar inferir estilos de vida diferentes, traduzido em um código linguístico diverso, e dos quais, muitas vezes, os vestígios perceptíveis se inscrevem apenas em nomes geográficos (DICK, 1990, p. 21).
\end{abstract}

Investigações toponímicas podem estar intrinsecamente ligadas ao resgate e à preservação da história e da cultura de um povo. Muitas vezes ocorre a "fossilização" de vocábulos que ficam na toponímia e análise desses itens é essencial para se terem pistas de línguas não mais faladas e pouco conhecidas. Por isso, Sampaio (1987, p. 63) afirma que “(...) preservar-lhes a grafia verdadeira e a verdadeira pronúncia, fixar-lhes o significado, interpretado através do véu obscuro dos metaplasmos, vale tanto como resguardar um monumento histórico".

No que se refere à estrutura do sintagma toponímico, a construção se dá, como já mencionado, por um elemento de caráter genérico e outro elemento de caráter específico, que, de acordo com Dick (1990) pode ser simples, composto ou híbrido. 
Conforme Dick (1990, p. 13), um elemento específico simples é aquele que é formado por apenas um elemento determinante, como, por exemplo: Fazenda Coqueiral, Fazenda Esperança. Ainda conforme a autora, um elemento específico composto é aquele que é formado por mais de um elemento determinante, sendo que os mesmos podem vir a possuir origens diversas "do ponto de vista do conteúdo", gerando, assim, formações inusitadas, como por exemplo: Sítio Água Azul, Fazenda Maninho Gaz.

Já um topônimo hibrido, de acordo com Dick (1990, p. 14), é aquele que possui em sua formação a presença de elementos linguísticos de mais de uma língua; nos casos que se discorrem neste artigo, nota-se a presença predominante de elementos linguísticos de origem portuguesa + indígena ou até mesmo de formações de origem espanhola + indígena, como por exemplo: Fazenda Francês Cue, Fazenda Modesto Cue, Fazenda Laguna Itá.

Por ser o conceito de hibridismo importante para o recorte analisado neste artigo, recorreu-se a outras fontes para confirmar se as definições se assemelham ou se ampliam. Assim, recorreu-se a uma gramática onde se registra:

\footnotetext{
Hibridismo - Chama-se hibridismo à formação de palavras com elementos de idiomas diferentes. São mais comuns os hibridismos constituídos da combinação de elemento grego com outro latino ou românico: sociologia (latino e grego), autossugestão (grego e português), televisão (grego e português) [...]. A nossa língua forma com facilidade hibridismos com elementos estrangeiros que se acham perfeitamente assimilados ao idioma, que passam como elementos nativos (BECHARA, 1999, p. 372).
}

Como se nota, a definição apresentada, obviamente, refere-se a itens do léxico comum e não exatamente aos nomes de lugares, mas menciona como mais comum um hibridismo resultante da mistura das línguas latinas, gregas e portuguesa. O mesmo se verifica em uma definição encontrada em um dicionário de linguística (que remete à gramática). 


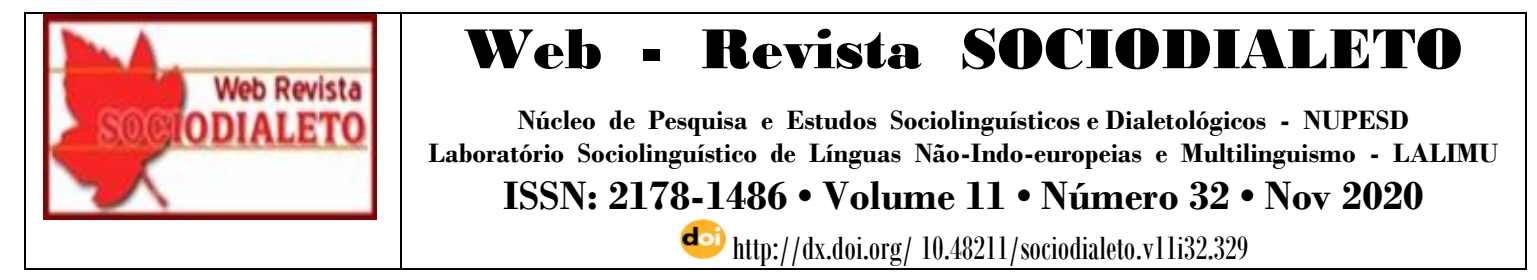

Híbrido: Em gramática tradicional, palavra híbrida é aquela cujos constituintes são tomados a raízes de línguas diferentes. Assim, automóvel, cujas raízes são autos (gr.), "por si mesmo" e mobilis (lat.), "que pode mover-se", é uma palavra híbrida (DUBOIS, 1973, p. 322-323).

Para análise dos dados deste estudo interessa os topônimos híbridos, formados por elementos da língua portuguesa e elementos de línguas indígenas. E, por se entender que a presença de elementos da língua espanhola reflete a situação de fronteira geográfica da região, também serão feitas algumas considerações a respeito.

\section{Análise dos dados}

Dos 86 nomes de acidentes geográficos humanos (aldeia indígena, estância, fazendas e sítios) coletados e analisados preliminarmente, verificou-se que $21 \%$ são de origem indígena e $6 \%$ são compostos por pelo menos um elemento de língua indígena. O Gráfico 01, na sequência, mostra a proporção desses topônimos em relação aos demais.

\section{Gráfico 01 - Procedência linguística dos topônimos}

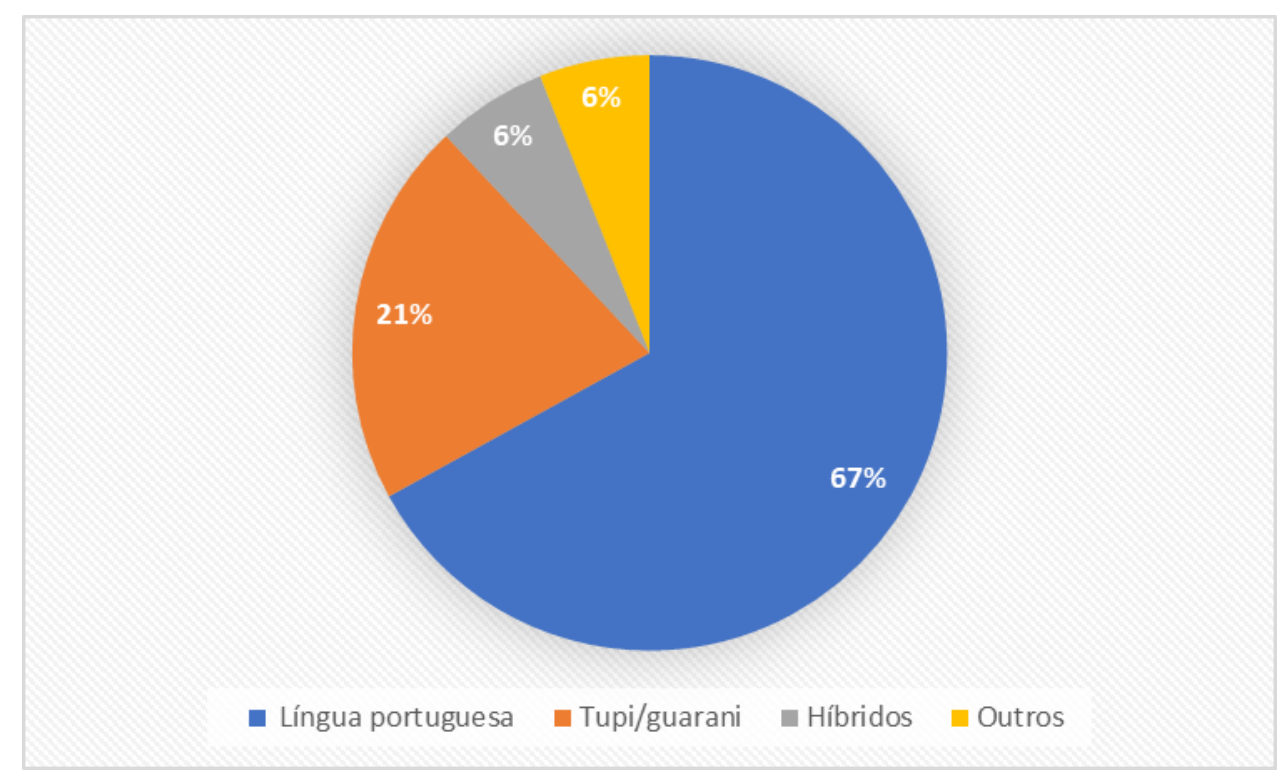

Fonte: as autoras 
Naturalmente, em geral, em qualquer recorte do território brasileiro, a língua portuguesa sobressairá no que se refere às procedências linguísticas dos topônimos. No caso específico do recorte tomado para este estudo, os percentuais verificados $(21 \%+$ 6\%) em relação a designativos de origem indígena e híbridos são significativos quando se consideram acidentes geográficos humanos ${ }^{7}$ (a maioria fazendas e sítios). Isso porque não são os indígenas os proprietários desses locais.

Assim, a motivação por trás das nomeações, em muito dos casos, pode estar relacionada com a troca cultural e lexical existente entre brasileiros, paraguaios e indígenas. Essa troca acontece em razão do contato constante, uma vez que a cidade está na fronteira com o Paraguai e a uma curta distância da Reserva Indígena Taquaperi.

É necessário considerar, no entanto, que nomes indígenas verificados nos acidentes humanos, muitas vezes, são transpostos de outros acidentes geográficos presentes na região. Assim, por exemplo, o Córrego Ivaé teria motivado a nomeação da Fazenda Ivaé. Em outras palavras, é possível observar, então, que são atribuídos aos acidentes físicos e, em vários casos, passam daí para os acidentes geográficos humanos.

Na sequência, apresentam-se dois quadros: um com os topônimos de origem indígenas, e outro com os topônimos híbridos (português + guarani ou tupi). Os quadros dividem os sintagmas toponímicos em elementos genéricos e elementos específicos e informam a classificação da motivação, conforme modelo de Dick (1990, p.31-34), adotado para este trabalho. Como se optou por analisar os designativos a partir da taxionomia, para a ordem alfabética, considerou-se a terceira coluna dos quadros (taxionomia).

Quadro 01 - Topônimos de origem indígenas e sua motivação

\begin{tabular}{|l|c|}
\hline Sintagma toponímico & Taxionomia \\
\hline
\end{tabular}

\footnotetext{
${ }^{7}$ Quando se considera a nomeação de acidente geográficos físicos (rios, córregos, morros...), o processo de nomeação é mais espontâneo e coletivo. Nesses casos, a presença de línguas indígenas na nomeação é muito mais recorrente.
} 


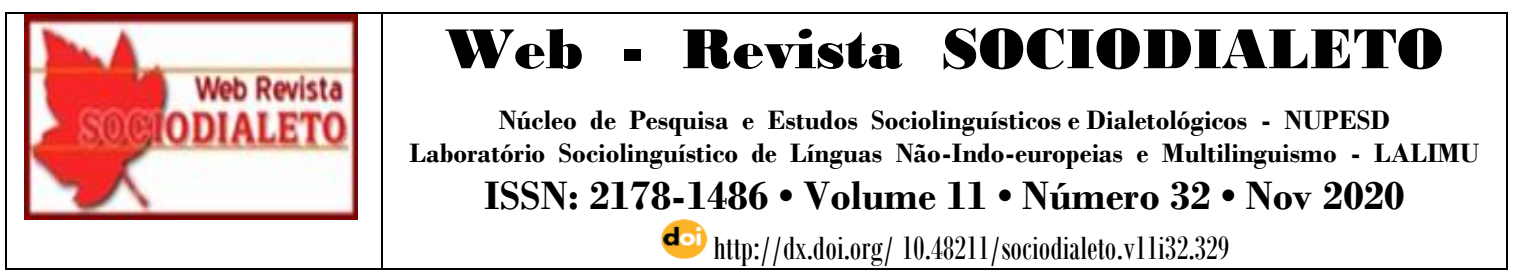

\begin{tabular}{|l|l|l|}
\hline \multicolumn{1}{|c|}{ elemento genérico } & \multicolumn{1}{|c|}{ elemento específico } & \\
\hline Fazenda & Guatá & (não classificado) \\
\hline Sítio & Morotim II & cromotopônimo \\
\hline Fazenda & Itapui & Litotopônimo \\
\hline Fazenda & Mangaí & Fitotopônimo \\
\hline Fazenda & Guapeí & Fitotopônimo \\
\hline Fazenda & Imbu & Fitotopônimo \\
\hline Sítio & Ipê I & Fitotopônimo \\
\hline Sítio & Ipê II & Fitotopônimo \\
\hline Fazenda & Ivaé & Fitotopônimo \\
\hline Fazenda & Jaraguá & Fitotopônimo \\
\hline Colônia indígena & Taquaperi-Mangaí & Fitotopônimo \\
\hline Sítio & Taquapiri & Fitotopônimo \\
\hline Fazenda & Tarumã & Fitotopônimo \\
\hline Fazenda & Aripuanã & Zootopônimopônimo \\
\hline Fazenda & Curussu-Ambánimo \\
\hline Fazenda & Garigui & \\
\hline Fazenda & hotopônimo \\
\hline
\end{tabular}

Fonte: Elaboração das autoras

Para interpretar esses topônimos e destacar a motivação do denominador (a partir da taxionomia de Dick, 1990), parte-se de sua tradução para a língua portuguesa, baseando-se na consulta a dicionários de línguas guarani, tupi e portuguesa (nos casos 
em que a lexia já está incorporada à língua portuguesa). Ou seja, as obras lexicográficas são, neste estudo, o principal apoio para a compreensão dos nomes, conforme se observa na sequência.

O vocábulo guatá - Fazenda Guatá - pode ser traduzido como "passear, andar, caminhar" (ASSIS, 2008, p. 62). Esse conteúdo semântico do nome não permitiu que ele fosse incluído em nenhuma das categorias do modelo adotado. Ou seja, pelo sentido registrado, não foi possível chegar, de forma mais objetiva, à motivação. Apenas se confirma que o nome é de origem indígena.

Conforme Sampaio (1987, p. 286), morotim - Sítio Morotim II - equivale a "muito branco, alvíssimo". Dessa forma, por remeter a uma cor, o topônimo foi classificado como cromotopônimo. A respeito desse nome, é importante destacar que, no município de Coronel Sapucaia, encontra-se o Córrego Morotim que, provavelmente, teria sido nomeado antes do sítio. Nesse caso, é possível pensar que a cor poderia ser referente ao aspecto da água do córrego e na transposição do nome para o sítio essa questão não é levada em conta, ou seja, apenas homenageia-se o córrego.

O item lexical itapuí - Fazenda Itapuí - equivale, conforme Sampaio (1987, p. 259), a "ITAPUY corr. Itá-poi, a pedra delgada, ou em folhetas [...]". Não se observou a ocorrência de outro elemento físico que poderia ter motivado o nome da fazenda, mas verificou-se que existe uma cidade do estado de São Paulo com o mesmo nome. Nesse caso, o dono da fazenda poderia ter transplantado o nome dessa cidade. Entretanto, como não foi possível confirmar essa informação, o topônimo foi classificado como litototopônimo por remeter a pedra.

A motivação relativa à vegetação se destacou entre os dados em estudo. Assim, os designativos geográficos que representam a categoria dos fitotopônimos, conforme também se observar no quadro 01, foram os seguintes: Fazenda Mangaí, Fazenda Guapeí, Fazenda Imbu, Sítio Ipê I e Sítio Ipê II, Fazenda Ivaé, Fazenda Jaraguá, Colônia Indígena Taquaperi-Mangaí e Fazenda Tarumã. Na sequência, apresentam-se as traduções desses vocábulos elevados à categoria de nome próprios, conforme as fontes lexicográficas consultadas: 
mangaí: variação de mangavý - "árvore da qual é extraído o látex (...). O mesmo que mangay" (SAMPAIO, 1986, 102).

guapeí: "planta ninfácea do Amazonas; vitória-régia" (TIBIRIÇÁ, 1989, p. 103).

imbu: "a árvore que dá de beber; alusão aos tubérculos grandes desta planta (Spondias uberosa), que, nas raízes segregam água e matam a sede dos viajantes em tempos de seca (...)" (SAMPAIO, 1987, p. 248).

ipê: "a árvore cascuda" (SAMPAIO, 1987, p. 251).

ivaé: "ivá hé - fruta saborosa” (TIBIRIÇÁ, 1989, p.77)

jaraguá: tipo de erva da família das gramíneas (Hyparrhenia rufa) (AULETE DIGITAL) $)^{8}$

taquaperi/taquapiri: taquaperi composto por duas palavras: taquara, que significa "o tronco ou haste furada" (SAMPAIO, 1987, p. 324) e pirí, que significa "o junco" (SAMPAIO, 1987, p. 298);

tarumã: nome de várias árvores e arbustos do gên. Vitex, da família das labiadas. (AULETE DIGITAL) ${ }^{9}$.

Além da vegetação, aspectos relativos à água também são fontes de motivação para os topônimos indígenas. Dentre os nomes analisados, foram classificados como hidrotopônimos Fazenda Aripuanã e Fazenda Ipanema. O vocábulo Aripuanã não foi localizado nos dicionários consultados, mas segundo o site Indígenas do Brasil, pode ser traduzido para a língua portuguesa como "água de pedra"10; o site do IBGE também registra essa informação: “A origem do nome Aripuanã é indígena Apiacá, que significa Água de Pedra"11. Já o vocábulo Ipanema é traduzido como "a água ruim, imprestável; o rio sem peixe, ou ruim para a pesca” (SAMPAIO, 1987, p. 251). Apesar do significado do nome, ele identifica local de prestígio em outra localidade (Rio de Janeiro). Os dois topônimos, Aripuanã e Ipanema, podem ter se deslocado juntamente com o migrante, pois Aripuanã também nomeia um município do estado de Mato Grosso.

\footnotetext{
${ }^{8}$ AULETE DIGITAL. Jaraguá. Disponível em: http://www.aulete.com.br/jaragua. Acesso em: 03 jul. 2020.

9 AULETE DIGITAL. Tarumã. Disponível em: http://www.aulete.com.br/tarumã. Acesso em: 03 jul. 2020.

${ }^{10}$ INDÍGENAS DO BRASIL: OS PRIMEIROS POVOS DO BRASIL. Yakarawakta. Disponível em: https://brasil.antropos.org.uk/327-yakarawakta/. Acesso em: 13 nov. 2019.

${ }^{11}$ INSTITUTO DE GEOGRAFIA E ESTATÍSTICA - IBGE. Histórico sobre Aripuanã. Disponível em https://cidades.ibge.gov.br/brasil/mt/aripuana/historico. Acesso em 30 jul. 2020.
} 
Ainda dentre os nomes de origem indígena, verificou-se o vocábulo barigui Fazenda Barigui - que, conforme Tibiriçá (1989, p. 73), significa “a mosca pequena". Pelo fato de se referir a um elemento do reino animal, o designativo foi classificado como zootopônimo.

Já o vocábulo curussu - de Fazenda Curussu-Ambá - pode ser traduzido, conforme Guasch e Ortiz (2001, p. 614), como “a Santa Cruz”; já o vocábulo ambá, no dialeto local, teria como significado "a imagem"12. Como tais significados referem-se a um objeto sagrado do cristianismo, o topônimo foi classificado como hierotopônimo. A respeito desse nome, é importante registrar que, no município, existe também o Córrego Curussu-Ambá, de onde, provavelmente, o nome teria sido transposto.

Alguns dos topônimos analisados já se encontram incorporados nos atuais dicionários de língua portuguesa e são comuns no cotidiano de comunicação dos brasileiros como, por exemplo: imbu e ipêe e, portanto, não configuram como particularidade regional; já outros nomes, como taquaperi, mangaí e ivaé são exemplos de vocábulos não dicionarizados em obras de língua portuguesa que pertencem à língua indígena em uso na região. A propósito, taquaperi é um vocábulo que se sobressai como particularidade pois serviu como referência para a nomeação de dois acidentes humanos rurais - Colônia Indígena Taquaperi-Mangaí e Sítio Taquapiri.

Sobre a presença de topônimos de origem indígena em território brasileiro, Sampaio (1987), há muito tempo, já fazia a seguinte indagação:

Quem de nós não terá, por vezes, inquirido pelo significado de tantos nomes estranhos, cuja pronunciação já corre adulterada e cujo sentido já ninguém compreende? E são, todavia, vocábulos doces e sonoros, longos muitas vezes, excelentes em geral como designação de lugares, mas que muitos perdem do seu valor, por não se saber o que exprimem, o que recordam, o que nos revelam do sentir e do gênio do povo primitivo que nô-los legou (SAMPAIO, 1987, p. 64).

\footnotetext{
${ }^{12}$ Como não se encontrou um significado para o nome nos dicionários consultados, a interpretação do vocábulo foi baseada em pesquisa oral com população local (apenas para esse item).
} 
Portanto, o estudo toponímico acerca dos acidentes rurais humanos de Coronel Sapucaia tem importância, entre outras razões, por buscar "elucidar" vocábulos indígenas presentes na região cujo significado não é de conhecimento geral. A pesquisa e a tradução dos nomes dão a eles uma transparência por meio da qual é possível chegar às motivações do denominador.

No Quadro 02 estão apresentados os topônimos considerados híbridos (português + guarani) seguidos também da motivação a que se chegou a partir da análise de cada um.

\begin{tabular}{|l|l|l|}
\multicolumn{2}{|c|}{ Quadro 02 - Topônimos híbridos e sua motivação } \\
\cline { 1 - 2 } Sintagma toponímico & \multirow{2}{*}{ Taxionomia } \\
\cline { 1 - 2 } elemento genérico & \multicolumn{1}{|c|}{ elemento específico } & \\
\hline Fazenda & Rincão Porã & animotopônimo \\
\hline Fazenda & Modesto Cuê & antropotopônimo \\
\hline Fazenda & Francês Cuê & etnotopônimo \\
\hline Sítio & Sanga Morotim III & geomorfotopônimo \\
\hline Fazenda & Laguna Itá & hidrotopônimo \\
\hline
\end{tabular}

Fonte: elaboração das autoras

Como já mencionado, o hibridismo ocorre quando uma palavra é constituída por elementos de línguas distintas. Esse é o caso dos topônimos do Quadro 02, formados por elementos da língua portuguesa e da língua guarani em uso na região pesquisada.

No nome rincão porã - de Fazenda Rincão Porã - tem-se o vocábulo "rincão", da língua portuguesa, que, segundo o Dicionário Caldas Aulete, significa "recanto; refúgio" ${ }^{13}$ e há também o vocábulo porã, do guarani, que pode ser traduzido como "bom, bonito, lindo (...)" (SAMPAIO, 1986, p. 131). Como se considera o primeiro elemento específico para a análise da motivação, o topônimo foi classificado como AULETE DIGITAL. Refúgio. Disponível em: http://www.aulete.com.br/refugio. Acesso em 08 jul 2020. 
animotopônimo, uma vez que o sentido expresso está relacionado à vida psíquica (como sensações, sentimentos etc.).

Em modesto cuê - de Fazenda Modesto Cue - tem-se o vocábulo Modesto, que, neste caso, refere-se ao nome próprio de uma pessoa, e o formante $\mathrm{Cue}$, do guarani que, conforme Sampaio (1987, p. 221), pode ser traduzido como "velho, antigo; o que já foi, o passado". Esse designativo geográfico foi classificado, quanto à sua motivação, como antropotopônimo. Convém ressaltar, a propósito do elemento "cue" (grafado com ou sem acento nos mapas consultados) que se trata de um elemento comum na formação de topônimos híbridos em outros municípios de MS. A título de exemplo, citam-se os seguintes: Cabeceira Tapeí-cuê (Amambai), Ribeirão Felix-Cuê (Angélica), Córrego Leite Cuê (Aral Moreira), Fazenda Oriental Cuê (Bela Vista).

Em francês cuêe - de Fazenda Francês Cuê - verifica-se o vocábulo francês da língua portuguesa - relativo à pessoa ou a algo originário da França e, mais uma vez, o vocábulo cuê, já mencionado. Esse topônimo foi classificado como etnotopônimo categoria toponímica que remete a elementos étnicos ou pátrios.

No designativo sanga morotim - de Sítio Sanga Morotim III - o vocábulo sanga, segundo o Dicionário Caldas Aulete, refere-se à “escavação funda produzida num terreno por chuvas ou correntes subterrâneas" "14; já o vocábulo guarani morotim, já mencionado, significa "muito branco, alvíssimo" (SAMPAIO, 1987, p. 286). Esse topônimo foi classificado como geomorfotopônimo em razão de sua motivação estar relacionada a uma formação geográficas.

Por fim, em laguna itá - de Fazenda Laguna Itá - encontra-se o vocábulo espanhol laguna que, traduzido para o português, significa "lagoa"15 e, também, encontra-se o vocábulo guarani itá que, conforme Sampaio (1987, p 254), pode ser traduzido como "o que é duro, a pedra". Esse topônimo foi classificado como hidrotopônimo uma vez que seu primeiro elemento é motivado por um acidente hidrográfico.

\footnotetext{
${ }^{14}$ AULETE DIGITAL. Sanga. Disponível em: http://www.aulete.com.br/sanga. Acesso em 08 jul 2020.

${ }^{15}$ MICHAELIS. Laguna. Disponível em: https://michaelis.uol.com.br/escolar-espanhol/busca/espanholportugues/laguna/ Acesso em 08 jul 2020.
} 


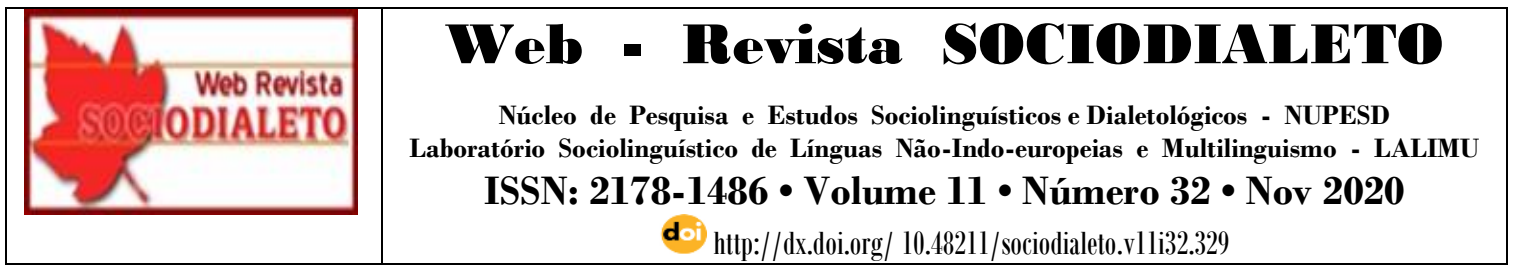

Considerando os topônimos indígenas e aqueles formados com pelo menos um elemento de língua indígena, apresenta-se o Gráfico 02 referente às taxionomias, ou seja, aos aspectos motivacionais dos nomes analisados.

Gráfico 2 - Taxionomias dos topônimos indígenas e híbridos

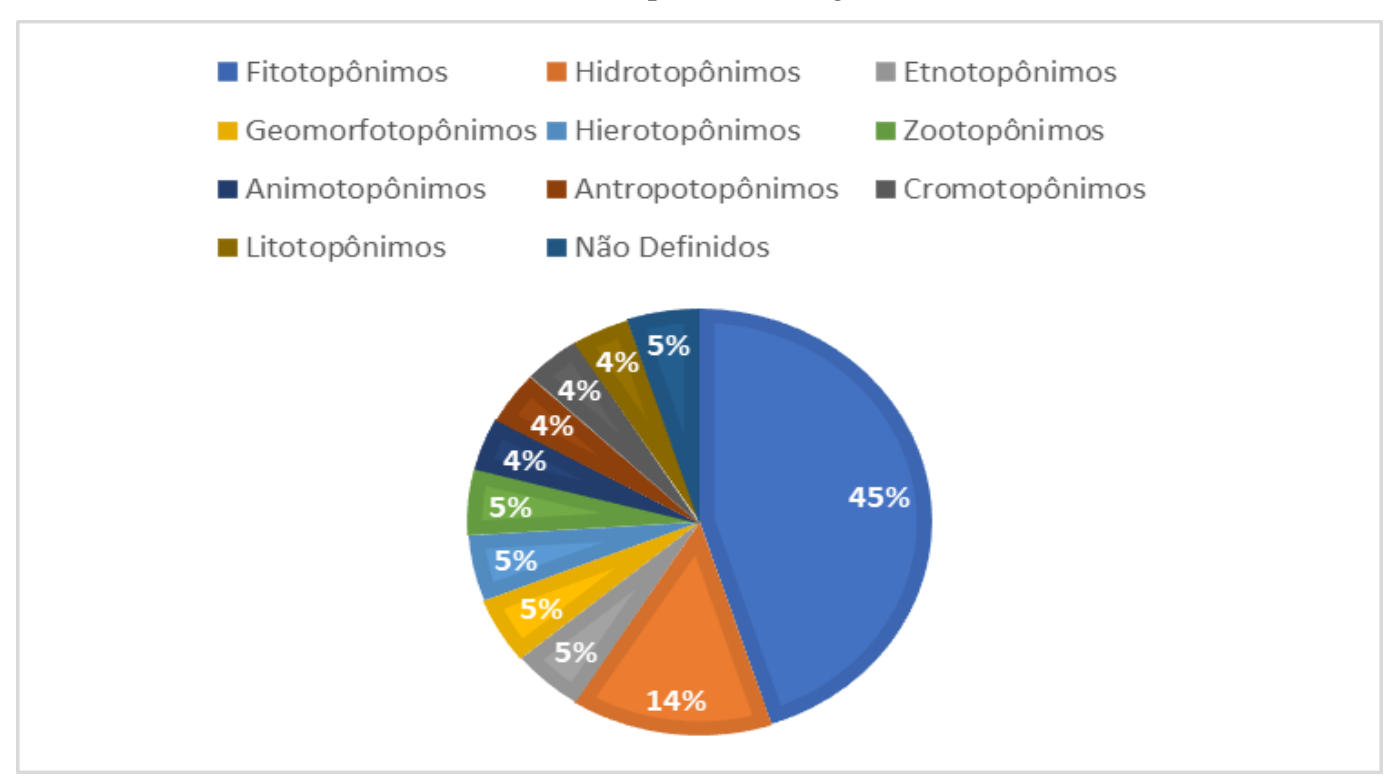

Fonte: as autoras

Conforme se observa, predominam os fitotopônimos (45\%), ou seja, os nomes inspirados pela vegetação; em segundo lugar, estão os topônimos formado por vocábulos que remetem à água, isto é, os hidrotopônimos (14\%). Outras categorias também foram representadas nesse recorte de designativos geográficos, a saber: etnotopônimos (5\%), geomorfotopônimos (5\%), hierotopônimos (5\%), zootopônimos (5\%), animotopônimos (4\%), antropotopônimos (4\%) cromotopônimos (4\%), litotopônimos (4\%) e topônimos não definidos (5\%). Essa sistematização das categorias comprova que, ao se analisarem topônimos indígenas, os elementos da natureza física se destacam, ou seja, são mais recorrentes.

Além dos topônimos indígenas e dos híbridos formados por elementos de língua indígena, chamaram a atenção ainda alguns nomes nos quais é possível observar uma influência da língua espanhola, que também está muito presente no cotidiano da 
fronteira mesmo no lado brasileiro. A análise desses nomes não era objetivo deste estudo, mas como a ideia principal é evidenciar como as questões ambientais interferem na nomeação, considerou-se que eles, igualmente, ilustram essa realidade. Assim, destacam-se os seguintes topônimos: Fazendo Cerro Alto, Fazenda Cero Péron, Fazenda Isla Lopes, Sítio Isla Lopes e Fazenda Lapacho.

No topônimo Fazenda Cerro Alto, o elemento específico é composto por dois vocábulos que integram o léxico da língua portuguesa e da língua espanhola. No entanto, cerro não é lexia de uso comum entre falantes de língua portuguesa da região estudada, que preferem "morro" ou "colina" para designar o mesmo referente. O dicionário Señas (2010, p.257) registra as seguintes informações para a palavra cerro: "Elevación de menor altura que una montaña" e informa "colina" como o equivalente em língua portuguesa. Assim, entende-se que o uso dessa lexia na toponímia do lado brasileiro da fronteira pode se relacionar à influência paraguaia. O mesmo ocorre com o topônimo Fazenda Cerro Perón em que Perón é sobrenome de origem espanhola, hipocorístico de Pedro, conforme atesta Guérios (1981, p.201). Nesse caso, entretanto, a influência do país vizinho parece mais evidente.

Nos topônimos Fazenda Isla Lopes e Sítio Isla Lopes, o primeiro vocábulo do elemento específico, isla, integra o léxico da língua espanhola e conforme o dicionário Señas (2010, p. 727) pode ser traduzido como "ilha". Nesses topônimos, entretanto, se constitui como nome de pessoa. Já Lopes é sobrenome de origem portuguesa (GUERIOS, 1981, p.161).

Dentre os nomes que podem estar na toponímia em razão da situação da fronteira, tem-se ainda Fazenda Lapacho. O vocábulo lapacho, de acordo com o Diccionario de la lengua española, do site da Real Academia Española, é "árbol de América del Sur, de la familia de las bignoniáceas" e, ainda, "madera del lapacho, fuerte e incorruptible, que se emplea en construcción y en ebanistería". Essa árvore é comum no Brasil, e é mais conhecida como "ipê".

\section{Considerações finais}


Conforme mencionado inicialmente, o objetivo principal deste estudo era apresentar considerações sobre um recorte da toponímia rural do município de Coronel Sapucaia - MS, destacando a influência indígena em designativos geográficos. Para tanto, partiu-se do pressuposto de que aspectos do ambiente sociocultural bem como a configuração espacial em que os nomes estão inseridos estariam, em alguma medida, refletidos nos nomes de lugares.

Sabe-se que os nomes indígenas estão espalhados pela toponímia de todo o território nacional. A maioria é de origem tupi e muitos estão incluídos nos dicionários de língua portuguesa, não sendo mais, portanto, particularidades de uma ou de outra região. Entretanto, quando a presença indígena se mantém mais intensamente em algumas regiões, outros designativos geográficos de procedências de línguas indígenas em uso efetivo, ainda não incorporados à língua portuguesa e aos seus dicionários, poderão ser encontrados.

Assim, no estudo realizado foram verificados nomes indígenas já incorporados à língua portuguesa (Sítio Ipê I e Fazenda Jaraguá, por exemplo) e nomes não incorporados (Fazenda Curussu-Ambá e Fazenda Ivaé, por exemplo). Além desses, ainda que não fosse objetivo inicial do trabalho, verificaram-se também topônimos de procedência espanhola como Fazenda Cerro Perón e Fazenda Lapacho. A ocorrência desse tipo de nome geográfico confirma o pressuposto de que aspectos extralinguísticos podem estar refletidos na língua, especialmente no léxico, representado, neste caso, pelos nomes próprios de lugar.

Convém registrar que a situação de fronteira propicia uma enorme confluência cultural e, sobretudo, linguística entre habitantes brasileiros (indígenas e não indígenas) e paraguaios. Isso acontece porque a fronteira é muito fluída, se apresentando apenas política e economicamente. Assim, essas características do ambiente - nos termos de Sapir (1961) - estão refletidas nas línguas que se falam na região e, nos topônimos, que são elementos das línguas, também se observam o reflexo dessa confluência cultural 


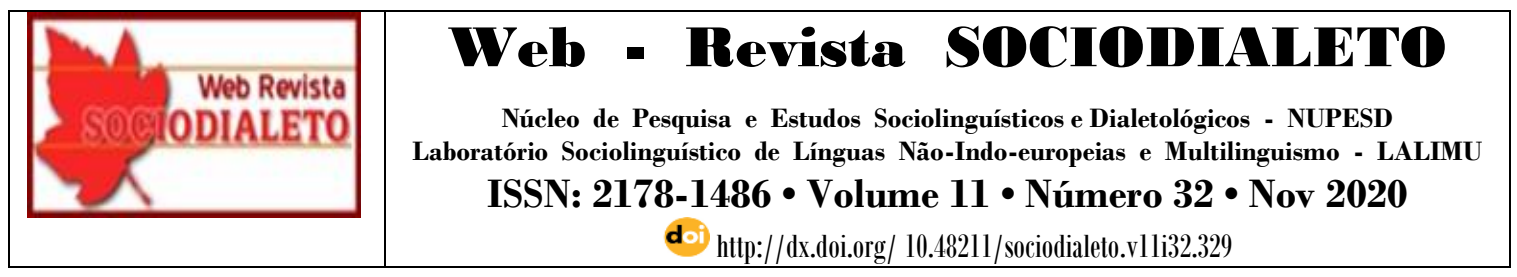

fronteiriça, em que as línguas se mesclam e as culturas convergem para criar um ambiente característico e único.

\section{Referências}

ASSIS, Cecy Fernandes de. Ñe'eryru Dicionário Guarani-Português / PortuguêsGuarani. São Paulo: Editora da autora, 2008.

AULETE DIGITAL. Disponível em: <www.aulete. com.br〉. Vários acessos.

BECHARA, Evanildo. Moderna Gramática Portuguesa. 37. ed. Rio de Janeiro: Nova Fronteira, 2009, p. 372, p. 590.

FERRARI, Márcio. B.F. Skinner, o cientista do comportamento e do aprendizado. Nova Escola, 01 de outubro de 2008. Disponível em: < https://novaescola.org.br/conteudo/1917/b-f-skinner-o-cientista-do-comportamento-edo-aprendizado >. Acesso em: 05 mai. 2020.

DICK, Maria Vicentina de Paula do Amaral. Toponímia e antroponímia no Brasil: Coletânea de estudos. 3. ed. São Paulo: Gráfica da FFLCH/USP, 1990.

DICK, Maria Vicentina de Paula do Amaral. Toponímia e Cultura. Rev. Inst. Est. Bras., São Paulo, n.27, p.93-101, 1987.

DUBOIS, Jean. et al. Dicionário de Linguística. São Paulo: Cultrix, 1973.

GUASCH, Antonio; ORTIZ, Diego. Diccionario castellano-guaraní; guaranícastellano. 13. ed. Paraguay: Centro de Estudios Paraguayos "Antonio Guasch". Asunción, Paraguay, 2001.

IBGE - INSTITUTO DE GEOGRAFIA E ESTATISTICA. Censo 2010. Disponível em censo2010.ibge.gov.br/. Acesso em: 17 nov. 2019.

IBGE - INSTITUTO DE GEOGRAFIA E ESTATISTICA. Coronel Sapucaia. Disponível em: <https://cidades.ibge.gov.br/brasil/ms/coronel-sapucaia/historico>. Acesso em: 01 dez. 2019.

MANSUR GUÉRIOS, Rosário Faráni. Dicionário etimológico de nomes e sobrenomes. São Paulo, Ave Maria, 1981 (3.a edição revista e ampliada).

MICHAELIS. Disponível em: < https://michaelis.uol.com.br/escolar-espanhol/>. Vários acessos.

PREFEITURA MUNICIPAL DE CORONEL SAPUCAIA. História de Coronel Sapucaia. Disponível em: 〈http://coronelsapucaia.ms.gov.br/pagina/78_Historia.html>. Acesso em: 01 dez. 2019.

REAL ACADEMIA ESPAÑOLA. Diccionario de la lengua española. Disponível em https://dle.rae.es/. Acesso em: 08 ago. 2020.

SAMPAIO, Teodoro. O Tupi na Geografia Nacional. 5. ed. Brasília: Companhia Editora Nacional, 1987.

SAMPAIO, Mario Arnaud. Vocabulário guarani português. Porto Alegre, L\&PM,1986.

SAPIR, Edward. Linguística como Ciência. 1. ed. Livraria Acadêmica, 1961. 
Núcleo de Pesquisa e Estudos Sociolinguísticos e Dialetológicos - NUPESD Laboratório Sociolinguístico de Línguas Não-Indo-europeias e Multilinguismo - LALIMU ISSN: 2178-1486 • Volume 11 • Número 32 • Nov 2020

SEÑAS: Diccionario para la enseñanza de la lengua española para brasileños. 3.ed. São Paulo: Ed. Martin Fontes, 2010.

TIBIRIÇÁ, Luíz Caldas. Dicionário guarani português. São Paulo: Traço Editora, 1989.

ULLMANN, Stephen. Semântica: uma introdução à ciência do significado. 3. ed. Lisboa: Fundação Calouste Gulbenkian, 1961, p. 161.

Recebido Para Publicação em 21 de setembro de 2020. Aprovado Para Publicação em 23 de outubro de 2020. 